\title{
COLOMBIA 2017: ENTRE LA IMPLEMENTACIÓN Y LA INCERTIDUMBRE*
}

\author{
Colombia 2017: Between Implementation and the Uncertainty
}

\author{
PAOLA FAJARDO-HEYWARD \\ Canisius College, Estados Unidos
}

\begin{abstract}
RESUMEN
Este artículo repasa los hechos más importantes del año en Colombia, principalmente la implementación del Acuerdo de Paz firmado entre el presidente Juan Manuel Santos y las Fuerzas Armadas Revolucionarias de Colombia (FARC) en 2016. La primera parte del artículo hace un balance de la implementación. La segunda parte repasa los principales indicadores económicos y algunos hechos que impactaron la economía nacional. La tercera y cuarta parte discuten las transformaciones del Gabinete Ministerial y la producción legislativa, respectivamente. La quinta parte discute la relación bilateral de Colombia con Estados Unidos y las consecuencias de la crisis Venezolana. La última sección ofrece algunas reflexiones sobre los temas que impactaran al nuevo gobierno colombiano.
\end{abstract}

Palabras clave: Colombia, FARC, implementación, derechos humanos, seguridad

\begin{abstract}
This article summarizes the political developments that took place in Colombia during 2017 and highlights the implementation of the Peace Accord signed between the Government of Colombia and the Revolutionary Armed Forces of Colombia (FARC) in 2016. The first section assesses of the implementation of the accord. The second section focuses on the performance of the main economic indicators during 2017. The third and fourth sections discuss changes to the President's Cabinet and the Legislative agenda, respectively. The fifth section reviews the relationship between Colombia and the United States, as well as the impact of the crisis in Venezuela. Finally, the article provides final thoughts about the issues that will influence the new administration of Colombia.
\end{abstract}

Keywords: Colombia, FARC, implementation, human rights, security

Agradezco la ayuda de Maria Carolina Franco y sus acertadas sugerencias así como los comentarios de los evaluadores que ayudaron a mejorar este artículo. 


\section{INTRODUCCIÓN}

El 2017 fue un año de incertidumbre. Superadas las dificultades de la firma del Acuerdo de Paz con las FARC, el país esperaba expectante las reformas asociadas con su implementación. Los estudios sobre conflictos señalan que la incertidumbre que rodea los cambios institucionales propios de la implementación de acuerdos de paz pone a prueba la voluntad de las partes, principalmente las guerrillas. En la mayoría de los casos, la desconfianza da lugar a la reactivación de los conflictos. Así, las probabilidades de alcanzar una paz duradera están relacionadas con el avance en la implementación (Walter 2002). Por estas razones, el 2017 fue importante para Colombia, pues reveló grandes obstáculos para la puesta en marcha implementación del acuerdo y, de este modo, la posibilidad de su fracaso.

Aunque la administración del presidente Juan Manuel Santos contó con un procedimiento legislativo especial para agilizar la implementación del acuerdo, ${ }^{1}$ la complejidad del entorno doméstico y externo dificultó este proceso. Primero, las divisiones en torno al acuerdo con las FARC se profundizaron, fortaleciendo a los partidos de oposición en el Congreso. Esto le restó capital político al gobierno y obstaculizó la aprobación de varios proyectos de ley. Así, mientras los temas relacionados con el cese del conflicto avanzaron, otras iniciativas importantes no se concretaron. Las fallas de la implementación generaron incertidumbre sobre la viabilidad de la de las reformas contempladas en el acuerdo.

Adicionalmente, hubo serias dificultades en materia de seguridad y presencia estatal en varias regiones del país. Aunque a nivel nacional la violencia disminuyó, el vacío dejado por la desmovilización de las FARC generó el reacomodamiento del poder territorial y, en consecuencia, incrementó los enfrentamientos armados entre actores ilegales. Esta violencia golpeó especialmente a los líderes sociales: los asesinatos selectivos contra defensores de derechos humanos se incrementaron de forma vertiginosa. Finalmente, las relaciones de Colombia con Estados Unidos y Venezuela impactaron la viabilidad de políticas relacionadas con temas incluidos en el Acuerdo de Paz, concretamente el manejo de los cultivos de coca y los recursos financieros para la paz.

Este artículo repasa estos eventos así como el impacto de ellos en el proceso de implementación del acuerdo. Para ello, está dividido en cinco partes. Primero, el artículo identifica los avances y desafíos de la implementación del Acuerdo de Paz. La segunda parte repasa los principales eventos que afectaron la economía nacional. La composición del gobierno y la producción legislativa son discutidas en la tercera y cuarta sección, respectivamente. La quinta revisa el entorno internacional. El artículo cierra con algunas reflexiones sobre el impacto de los eventos de 2017 en el futuro del acuerdo bajo la nueva administración que se elija en las elecciones de 2018. 


\section{LA IMPLEMENTACIÓN DEL ACUERDO DE PAZ}

El Acuerdo de Paz firmado entre el Gobierno y las FARC consiste en seis puntos: reforma rural integral, participación política, cese al fuego y de hostilidades, solución al problema de las drogas ilícitas, víctimas y mecanismos de implementación y verificación (Alto Comisionado para la Paz 2016). El año se inició con la expectativa sobre la agenda que el presidente Santos propondría al Congreso para adoptar las leyes y reformas constitucionales necesarias para implementar los contenidos de estos puntos. Aunque se esperaba que el procedimiento legislativo especial para la paz, conocido como fast track, facilitara dicha implementación, en realidad la negociación política resultó más compleja de lo esperado. Hay varias razones que explican esta complejidad.

En primer lugar, la administración llegó al final de su mandato sin respaldo político. A la baja popularidad del gobierno registrada en 2016 (Rodríguez-Raga 2017) se sumó el tema de la corrupción. En enero, el escándalo de la compañía brasileña Odebrecht involucró, entre otros políticos colombianos, al presidente. Según documentos revelados en 2016, la campaña de reelección del mandatario en 2014 habría recibido un millón de dólares de esta compañía brasileña (El Espectador 2017, 25 de julio). La noticia impactó la percepción nacional: en 2017, Colombia bajó seis puestos en el Índice de Percepción de la Corrupción (Transparencia Internacional 2018). La baja popularidad no repuntó durante el año: los niveles de aprobación más altos se registraron en marzo, cuando el gobierno alcanzó un 24\% de aprobación (YanHass 2017). Inclusive en el tema de la implementación de la paz la opinión pública fue negativa: el 70\% de los encuestados descalificó la gestión del gobierno (León 2017). Esto fortaleció a los sectores políticos que se opusieron a la administración Santos y al Acuerdo de Paz.

En segundo lugar, tanto el fin del periodo presidencial como las elecciones de 2018 limitaron el margen de maniobra político de la administración. La oportunidad de participar en las elecciones motivó la renuncia de varios ministros, quienes habían sido clave para impulsar importantes proyectos de ley en el Legislativo. Igualmente, y con miras a las elecciones de 2018, durante el 2017 el Partido Cambio Radical (CR) buscó distanciarse del presidente Santos (El País 2017, 10 de octubre). En octubre, y en relación con las diferencias sobre puntos relacionados con el sistema de justicia para la paz, CR se retiró del gobierno. Estos hechos diezmaron el liderazgo político de la administración e impidieron consolidar el respaldo necesario para la agenda de paz en el Congreso. En consecuencia, a finales del año solo el 18,3\% de los puntos incluidos en el acuerdo fue implementado (OIAP 2018). 


\section{Los avances}

Los avances más importantes en la implementación se lograron en los puntos relacionados con el fin del conflicto (Kroc Institute 2017; OIAP 2018). Aspectos como el cese al fuego, la dejación de armas y la ubicación de miembros de las FARC en las zonas designadas para su desmovilización se implementaron en su totalidad. La misión de las Naciones Unidas recolectó 8.994 armas así como granadas, explosivos, minas antipersonales, entre otros (Naciones Unidas 2017, aparte 23). Estos avances tuvieron importantes consecuencias. El cese del conflicto con las FARC evitó la muerte de 2.796 personas, en su mayoría miembros de la guerrilla y de la fuerza pública (1.553 y 556 respectivamente) (CERAC 2017, 30 de junio). En 2017 el Hospital Militar, centro médico de las fuerzas armadas, recibió 24 personas heridas en combate, una disminución importante considerando que en 2012 el número de heridos en combate atendidos en este hospital fue de 388 (Presidencia de la República 2017, 23 de noviembre). También, y como se aprecia en la Figura 1, el número de homicidios registrado a nivel nacional disminuyó durante 2017 (Ministerio de Defensa 2018).

Figura 1. Homicidios a nivel nacional en Colombia 2011-2017

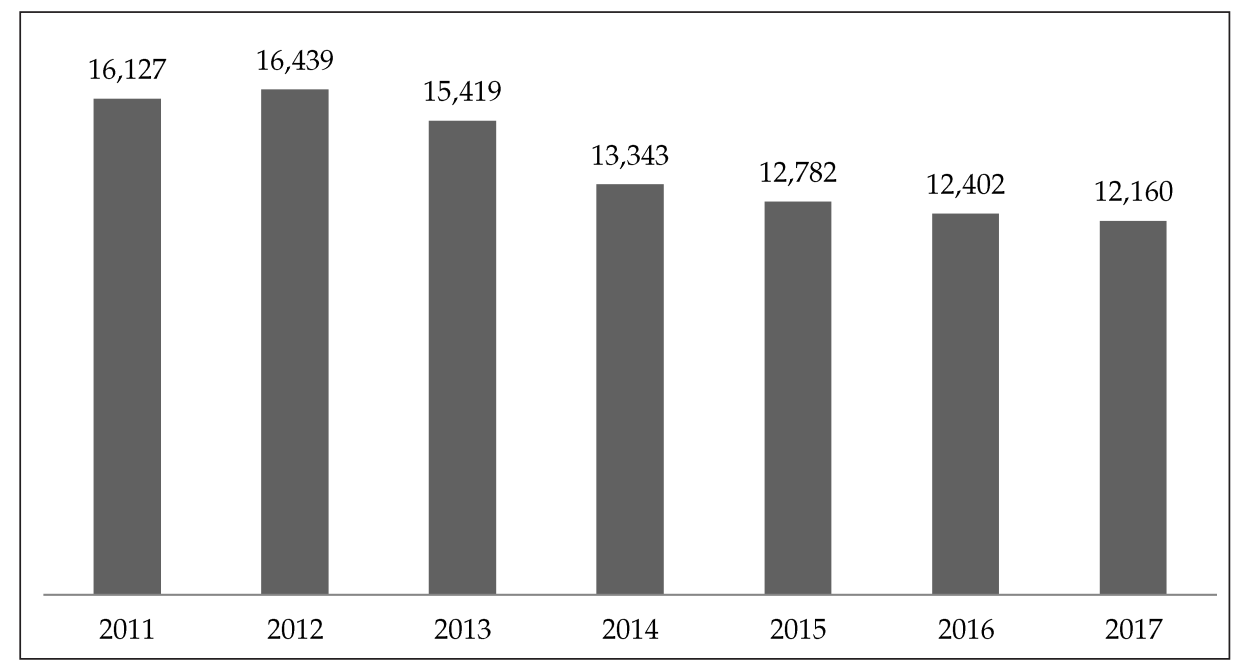

Fuente: Ministerio de Defensa (2018: 9)

Igualmente, se avanzó significativamente en la reincorporación política de las FARC, ya que se reglamentaron la amnistía y los indultos, resolviendo así la situación jurídica de los guerrilleros acusados de rebelión y delitos afines (El Espectador 2017, 20 de julio). Además, se creó el partido político de la guerrilla: el movimiento Fuerza Alternativa Revolucionaria del Común (FARC), el cual tendrá 10 curules en el Congreso ( 5 en la Cámara y 5 en el Senado) por dos periodos legislativos: 2018 y 2022. 
De otro lado, y aunque la implementación con relación al punto de víctimas tan solo fue del 9\% (OIAP 2018), las normas adoptadas en este tema fueron importantes. Primero, se creó el Sistema Integral de Verdad, Justicia, Reparación y no Repetición, que contiene agencias como la Unidad Especial de Búsqueda de Personas Desaparecidas, la Comisión para el Establecimiento de la Verdad, la Jurisdicción Especial para la Paz-JEP (que incluye el Tribunal para la Paz), entre otras. También fueron nombrados los magistrados del Tribunal para la Paz y su presidente, así como los directores de la Comisión para el Esclarecimiento de la Verdad y la Unidad de Búsqueda (Verdad Abierta 2017, 23 de noviembre).

El trámite institucional del Sistema de Justicia del post-acuerdo no se dio sin sobresaltos: la aprobación de la JEP generó gran polarización e inclusive, como se mencionó, la salida de Cambio Radical de la coalición partidista del gobierno. Por ende, hubo dos grandes cambios en este tema. Primero, la norma estatutaria que regula la JEP aprobada por el Congreso prohibió a personas que hubiesen defendido a víctimas de violaciones de derechos humanos (en tribunales nacionales e internacionales) posicionarse como magistrados en el Tribunal de Paz. Esta discriminación contra los defensores de derechos humanos motivó críticas por parte de varias organizaciones (El Espectador 2017, 16 de noviembre). Segundo, y en contravía de lo pactado en el acuerdo, la Corte Constitucional eliminó la competencia de la JEP para juzgar a los no combatientes acusados de crímenes cometidos durante el conflicto. La decisión fue rechazada por las organizaciones de víctimas, que esperaban que la JEP resolviera varios de los casos contra terceros involucrados en el conflicto (Verdad Abierta 2017, 16 de noviembre).

Finalmente, el respaldo de la Corte Constitucional al acto Legislativo 02 de 2017 fue también un avance. Esta norma garantiza la estabilidad jurídica del Acuerdo Final, y asegura que las tres futuras administraciones presidenciales respeten, financien y ejecuten los acuerdos (Semana 2017, 11 de octubre). El pronunciamiento de la Corte fue especialmente importante tras un año de creciente incertidumbre y pocos logros en materia de implementación.

\section{Los temas pendientes}

Si bien es cierto que la desmovilización de las FARC y su transformación en partido político se cumplieron, la reincorporación social y económica no avanzó de la misma manera. Las zonas a las cuales se desplazaron los individuos desmovilizados presentaron falencias importantes. Varias no contaban con infraestructura básica y algunos fueron ubicados en territorios con alta presencia de bandas criminales y explotación ilegal de recursos (cocaína y oro) (Álvarez y Pardo 2017). Adicionalmente, la demora en el desembolso de los recursos necesarios para programas de reincorporación generó un alto grado de desconfianza entre los desmovilizados. Se estima que tan solo un $45 \%$ de los 
8.000 desmovilizados que entregaron las armas en mayo permanecieron en las zonas especiales (Misión de Verificación ONU, 2017).

De otro lado, varias de las reformas necesarias para la implementación de temas importantes para la consolidación de la paz no lograron concretarse, especialmente la reforma rural integral (RRI). El asunto de la tierra en el país es bastante complejo: Colombia presenta la mayor desigualdad en la distribución de tierras en América Latina (OXFAM 2017: 13). Debido a la importancia del tema del territorio para la solución del conflicto, la RRI incluyó tres ejes: el acceso y uso de la tierra, la creación de planes nacionales de reforma rural integral y la creación de Programas de Desarrollo con Enfoque Territorial (PDETs). La implementación de los dos primeros ejes fue bastante baja: solo un $4 \%$ de las acciones necesarias en el tema de acceso y uso de la tierra fue implementado "plenamente" (Kroc Institute 2017: 40). En cuanto a los Planes Nacionales, al final de 2017 ninguna de las disposiciones que iniciaron tramite durante este año fueron ejecutadas (Kroc Institute 2017: 45).

Pese a la baja implementación de la RRI, hubo avances en los Programas de Desarrollo con Enfoque Territorial (PDETs). Creados a través de Decreto del Gobierno en mayo (Decreto Ley 893), los PDETS buscan involucrar en la reforma rural a la población de las áreas más afectadas por el conflicto armado, la pobreza, la presencia de economías ilícitas y la debilidad institucional (Presidencia 2017, 17 de julio). Si bien la Agencia de Renovación del Territorio (ART), encargada de la implementación de los PDETs, ha hecho presencia en la mayoría de los territorios, el esfuerzo institucional no se articuló adecuadamente con planes existentes o con otras iniciativas relacionadas con diversos puntos del acuerdo de paz (Abril y Uribe 2018). De otro lado, la falta de claridad sobre la implementación de los PDETs generó incertidumbre entre la población (Junieles 2017). Los PDETs son un punto clave de la transformación del campo en Colombia. Si bien las negociaciones con las comunidades avanzaron durante 2017, 2018 será clave para la implementación de estos programas.

El otro gran tema en el que se avanzó apenas parcialmente fue el de las drogas ilícitas. Pese a que el acuerdo incluyó temas relacionados con el narcotráfico y la salud pública, el gobierno se concentró en la sustitución de cultivos. Para 2017 la meta fijada fue la erradicación de 100 mil hectáreas de cultivos a través de planes de sustitución voluntaria y erradicación forzada (El Tiempo 2017, 9 de enero). Para esto se creó el Programa de Nacional Integral de Sustitución de Cultivos de Uso Ilícito (PNIS) responsable de la coordinación de la sustitución voluntaria. 
Tabla 1. Área Neta Cultivos de Coca

\begin{tabular}{lrrrrc}
\hline & \multicolumn{5}{c}{ Número de hectáreas con cultivos de coca } \\
\hline & 2012 & 2013 & 2014 & 2015 & 2016 \\
\cline { 2 - 6 } & 47.790 & 48.189 & 69.132 & 96.084 & 146.139 \\
$\begin{array}{l}\text { Oficina de las Naciones } \\
\begin{array}{l}\text { Unidas contra la Droga y } \\
\text { el Delito (UNODC) }\end{array}\end{array}$ & & & & \\
$\begin{array}{l}\text { Departamento de Estado, } \\
\text { Estados Unidos }\end{array}$ & 78.000 & 80.500 & 112.000 & 159.000 & 188.000 \\
\hline
\end{tabular}

Fuente: Beittel (2017: 35) y UNODC (2017: 24)

Priorizar la sustitución fue una decisión relacionada con el inusitado aumento en el área de cultivos ilícitos. Como se muestra en la Tabla 1, en 2016 se registraron 146 mil hectáreas de cultivos de coca, lo que hizo de Colombia el mayor productor de cocaína en el mundo (UNODC 2017). Debido a esto, el gobierno centró sus esfuerzos en la sustitución y erradicación, dejando de lado las otras iniciativas incluidas en este tema.

El progreso en la erradicación de cultivos presentó varios problemas. Durante el año, el PNIS firmó acuerdos con 127 mil familias, de las cuales 54 mil fueron vinculadas al programa de sustitución (Garzón y Suárez 2018: 6). Si bien los planes contemplan la entrega de recursos financieros y técnicos, procedimientos burocráticos entorpecieron dicho desembolso (Fundación Paz y Reconciliación 2017: 13). Las denuncias por el incumplimiento del gobierno se incrementaron con el correr del año y generaron desconfianza entre las comunidades cocaleras (El Espectador 2017, 13 de septiembre).

La inseguridad obstaculizó también la erradicación de cultivos. En las regiones donde se adelantó la sustitución de cultivos la inseguridad aumentó un 33\% (Garzón y Suárez 2018: 26). Este incremento se explica en parte por dos razones. En primer lugar, ante la falta de presencia estatal, los territorios anteriormente controlados por las FARC se convirtieron en escenario de disputa entre varios actores: las disidencias de las FARC, cuyo tamaño oscila entre ochocientos o mil individuos (El Tiempo 2017, 25 de octubre; Méndez 2017; The International Crisis Group 2017: 3); el Ejército Popular de Liberación (EPL), el Ejército de Liberación Nacional (ELN), ${ }^{2}$ las organizaciones criminales y los grupos paramilitares (Corporación Nuevo Arco Iris 2017). El gobierno respondió a esta violencia con operaciones militares encaminadas a neutralizar los grupos ilegales así como consolidar la presencia militar (El Tiempo 2017, 27 de septiembre).

La inseguridad también aumentó debido a los conflictos generados por la estrategia de erradicación forzada realizada por el ejército. En varias

2 Como se menciona más adelante, durante 2017 la administración del presidente Santos sostuvo negociaciones con esta organización; pese a esto, las acciones bélicas continuaron. 
oportunidades, las comunidades resistieron la presencia militar, lo que ocasionó enfrentamientos que en oportunidades culminaron en la muerte de varios campesinos (Garzón y Suárez 2018: 17; De Justicia 2017). El representante en Colombia de la Oficina de Naciones Unidas contra la Droga y el Delito expresó preocupación por el uso de medidas represivas en varias operaciones de erradicación forzosa (El Espectador 2017, 3 de noviembre). Los conflictos también se generaron debido a problemas de coordinación entre las instituciones estatales responsables de la sustitución voluntaria y la erradicación forzada. Las denuncias de campesinos cocaleros evidenciaron que unidades del ejército intentaron ejecutar labores de erradicación en territorios de comunidades que firmaron acuerdos de erradicación voluntaria con el PNIS (El Espectador 2017, 13 de septiembre).

Pese a estos problemas, al final del año el gobierno presentó un balance positivo. Según cifras reportadas por el Ministerio de Defensa, 52 mil hectáreas de cultivos de coca fueron erradicadas en 2017 (Ministerio de Defensa 2018: 40). Los datos presentados por el PNIS sugieren que la sustitución voluntaria alcanzó unas 124 mil hectáreas de coca (Alta Consejería Presidencial para el Postconflicto 2017). Empero, otras fuentes sostienen que la información disponible hace imposible estimar el número de hectáreas erradicadas de forma voluntaria (Garzón y Suárez 2018). Más allá de las cifras, el primer año de la sustitución mostró varias dificultades: la falta de coordinación entre agencias del gobierno, la dilación en la entrega de recursos, así como el desequilibrio entre la sustitución y las medidas de largo aliento necesarias para cambiar la realidad rural Colombiana. Los recursos asignados por el gobierno para infraestructura han sido importantes pero no suficientes. Una estrategia menos centrada en el corto plazo de la erradicación hubiera permitido usar recursos para mejorar las condiciones productivas en las zonas cocaleras e incrementar la legitimidad del Estado en estas regiones.

\section{El gran desafío: garantías para la participación política y el respeto a la vida}

El tema de la participación política fue incluido en el acuerdo para mejorar la falta de pluralismo y representación en Colombia. Los temas mencionados en este punto son: 1) el estatuto para la oposición política, 2) las medidas efectivas para promover una mayor participación política de todos los sectores, y 3) los mecanismos de participación política y garantías a la protesta pacífica. Según el reporte del OIAP, $19 \%$ de las iniciativas relacionadas con estas tres metas fue implementado durante el 2017, siendo el mayor logro la aprobación del estatuto de la oposición.

Los intentos de la administración Santos por tramitar iniciativas relacionadas con este tema enfrentaron una fuerte resistencia en el Legislativo. Concretamente, los debates del proyecto de la reforma política y las circunscripciones de paz 
se caracterizaron por enjundiosos choques entre la oposición y la coalición del gobierno (Semana 2017, 2 de diciembre). La reforma política, por ejemplo, pasó siete meses en el Congreso y al final se hundió por falta de apoyo. El proyecto de las circunscripciones de paz generó un dramático enfrentamiento entre el gobierno y el Senado. Este proyecto pretendía crear 16 curules temporales en el Congreso para corregir la falta de representación de territorios rurales y las zonas más afectadas por el conflicto (Fundación Paz y Reconciliación 2017: 6). Sin embargo, como se discute más adelante, el proyecto no logró aprobarse. Las fallas en estos dos proyectos evidenciaron la incapacidad del gobierno de persuadir a la clase política y al país de la necesidad de implementar uno de los puntos importantes del acuerdo, como es la ampliación de la participación política. Más aún, la oposición acérrima a estos proyectos es una muestra de la falta de apoyo por parte de la clase política a cualquier intento por ofrecer a las víctimas del conflicto una oportunidad directa para participar en la política nacional.

De otro lado, la implementación de medidas relacionadas con la seguridad de líderes sociales y excombatientes, también incluidas en el punto de participación política, fue bastante baja (Kroc Institute 2017: 30). El principal avance fue la creación del Sistema Integral de garantías de Seguridad para el Ejercicio de la Política (SISEP). Este sistema incluye un conjunto de protecciones para los movimientos sociales y los defensores de derechos humanos. En el sistema se articulan agencias de la Policía Nacional, el Ministerio del Interior y la Fiscalía. De todas formas, el SISEP no funcionó como se esperaba, en parte por su debilidad institucional y en parte por la falta del desarrollo de otras medidas necesarias para su funcionamiento (Verdad Abierta 2017, 23 de noviembre).

Las falencias del sistema de seguridad son importantes dada la crisis en esa materia registrada en varios territorios del país. Dicha inseguridad tuvo consecuencias funestas sobre la población civil de territorios tradicionalmente azotados por el conflicto. El Alto Comisionado de las Naciones Unidas para los Derechos Humanos en Colombia afirmó que durante 2017 la violencia contra líderes sociales produjo 441 ataques y 121 asesinatos (El Tiempo 2018, 20 de marzo). Organizaciones no estatales estiman que el número es más alto y llega a los 191 asesinatos (Indepaz y Marcha Patriotica 2018; Programa Somos Defensores 2018: 62; González y Delgado 2018). Al parecer, las víctimas venían preparándose para asumir tareas de liderazgo en el marco de la apertura política incluida en el acuerdo. Investigaciones también indican que fueron individuos que resistieron las acciones de actores armados (El Espectador 2018, 18 de febrero; Indepaz et al. 2017: 47). Por ende, puede decirse que la violencia contra líderes sociales no es aislada sino sistemática. 
Mapa 1. Asesinatos a defensores y defensoras de derechos humanos por departamentos 2017

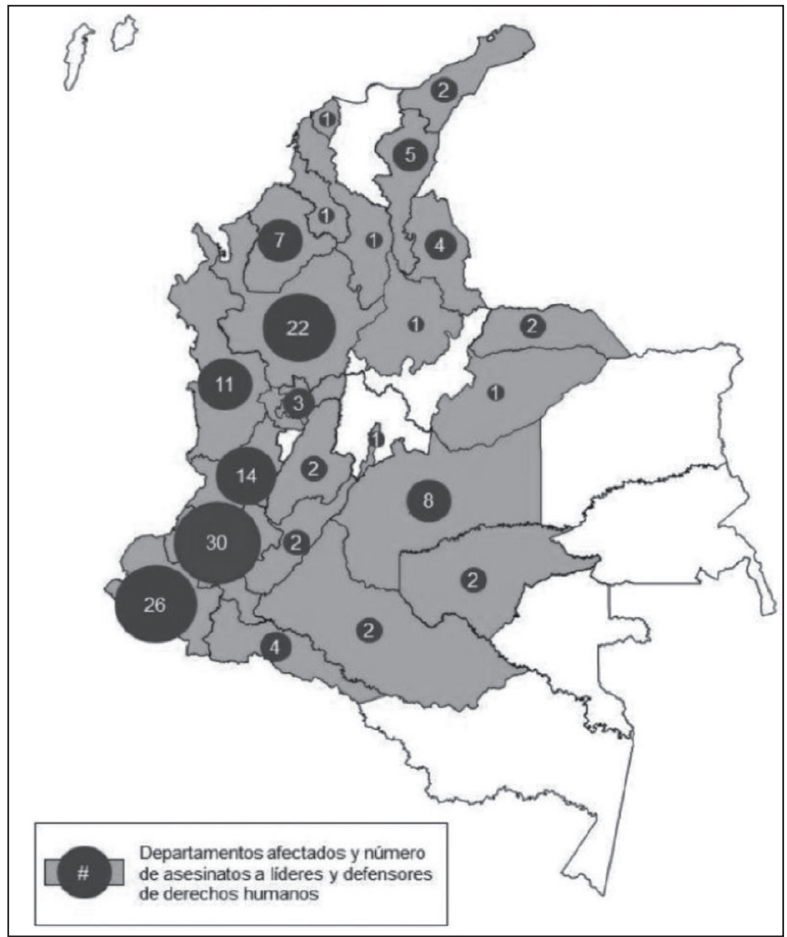

Fuente: Gonzáles y Delgado (2018)

Como respuesta a este problema, en diciembre el Ministerio de Defensa lanzó el plan Orus que buscaba reforzar la presencia militar en varios municipios del país (El Colombiano 2017, 11 de diciembre). El mismo mes, el ministro de Defensa afirmó que los asesinatos se debían a problemas personales ("líos de faldas") y no a un ataque sistemático (El Espectador 2017, 17 de diciembre). Lo anterior demuestra la fórmula del gobierno para enfrentar la violencia contra líderes sociales, que consiste principalmente en medidas de seguridad que no se acompañan con autoridades civiles necesarias para investigar la naturaleza de los crímenes. Adicionalmente, al desconocer la naturaleza sistemática de los ataques, el gobierno contribuyó a estigmatizar y deslegitimizar la labor de los líderes sociales, lo que exacerbó el clima existente de impunidad de los crímenes contra defensores de derechos humanos. Cifras disponibles indican que el 87\% de los actos cometidos contra defensores de derechos humanos entre el 2009 y el 2016 no ha sido resuelto (Programa somos Defensores 2017: 1). 
Figura 2. Líderes asesinados por mes 2017

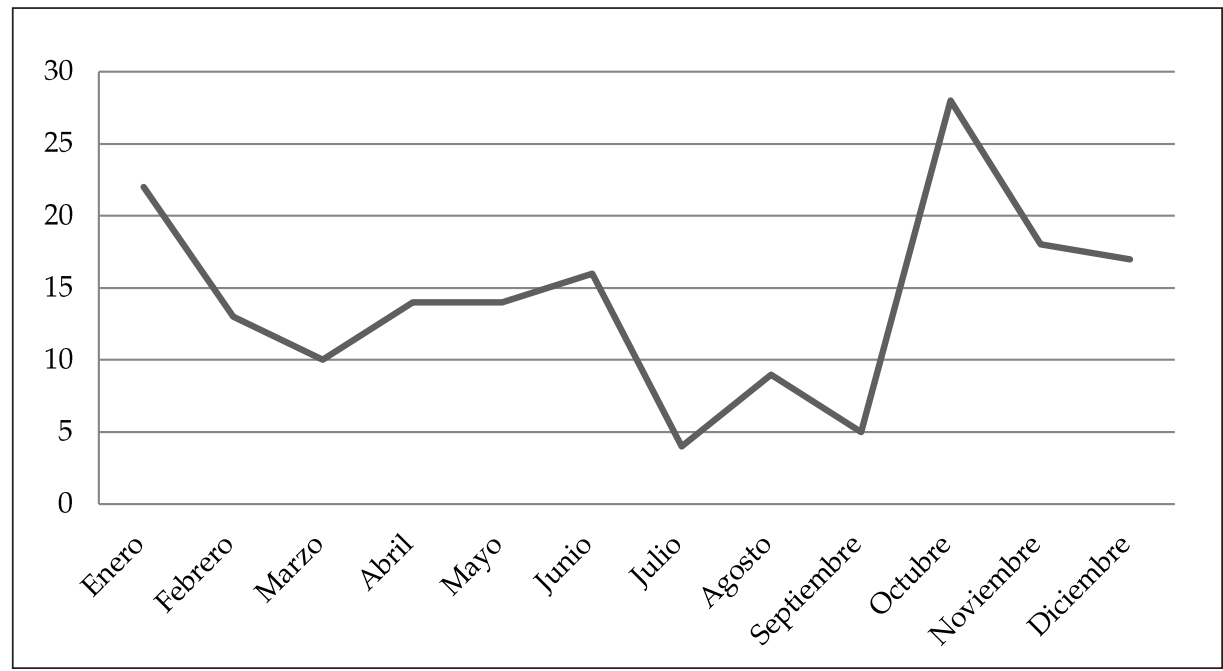

Fuente: Somos Defensores (2018)

En sistemas democráticos, la protección del respeto a la vida de los líderes sociales es responsabilidad del Estado. Pese a que el acuerdo enfatizó la necesidad de crear mejores condiciones para la defensa de los derechos humanos y la participación democrática, el gobierno no demostró su compromiso con este punto. La administración Santos desatendió las denuncias sobre estos ataques y adoptó una política poco contundente con relación a las garantías para los derechos humanos. Debido a que los líderes estaban involucrados con temas incluidos en el Acuerdo como la ampliación de la participación política, la reforma rural y los cultivos ilícitos, la falta de acción para responder a esta crisis cuestiona la voluntad del gobierno de dar cumplimiento a las reformas incluidas en estos temas, lo cual pone en peligro la viabilidad de la paz.

\section{Negociaciones con el Ejército de Liberación Nacional (ELN)}

Las negociaciones con esta guerrilla se iniciaron en febrero y progresaron lentamente debido a las diferencias en los temas del secuestro y el cese al fuego (Gómez 2017). Finalmente, el cese al fuego comenzó en octubre de 2017. Sin embargo, los enfrentamientos con bandas criminales y otras guerrillas no se detuvieron, así como tampoco las acusaciones de ambas partes sobre la violación del cese (Jiménez 2017: 15). Al respecto, al menos dos violaciones por parte del ELN fueron documentadas (CERAC 2017, 1 de diciembre). En diciembre, el jefe negociador del gobierno, Juan Camilo Restrepo, renunció a su posición (CNN en Español 2017, 5 de diciembre). Debido a estos hechos, el año cerró con grandes preguntas sobre la viabilidad del proceso de paz con esta guerrilla. 


\section{ECONOMÍA}

Para la economía nacional, 2017 fue un año difícil. Las estadísticas indican que los sectores de la minería, construcción e industria no crecieron, mientras que los sectores agrícolas, de establecimientos financieros y seguros, y el sector de servicios sociales, comunales y personales lograron un buen desempeño (DANE 2018: 3). El Producto Interno Bruto (PIB) creció tal solo en un 1,8\%, cifra inferior a los índices alcanzados en 2016 (2\%) y 2015 (3,1\%). Aunque modesto, el crecimiento de la economía colombiana superó el promedio de crecimiento regional que para 2017 fue del 1,3\% (CEPAL 2017).

La falta de dinamismo en la economía impactó en el desempleo y la inflación. Para el 2017 la tasa de desempleo en Colombia fue del 9,4\%, cifra ligeramente superior al 9,2\% registrado en el 2016 (DANE, 2017a). La inflación fue del 4,09\%, superando la meta del $3 \%$ fijada por el Banco de la República. Según esta entidad, el incremento en el Índice de Precios se debió a la reforma tributaria de 2016 y a la variación en precios en sectores relacionados con diversión, educación y comunicaciones (Banco de la República 2018: 52).

Otros eventos de 2017 evidenciaron la inconformidad con la calidad de vida en algunas partes del país e impactaron en la economía. Continuando las protestas sociales que caracterizan a la administración Santos (Montilla 2014: 107), durante el año las comunidades de Quibdó (El Chocó) y Buenaventura (Valle del Cauca) se declararon en paro cívico. En El Chocó, 59,8\% de la población vive en condiciones de pobreza y el índice de necesidades insatisfechas es de $79,19 \%$ (DANE 2017b). En Buenaventura, cerca del 66\% de la población vive en condiciones de pobreza (El Tiempo 2017, 10 de mayo). Debido a que este municipio es la entrada de la mitad de los productos importados en Colombia, el paro en Buenaventura generó pérdidas cercanas a los 300 mil millones de pesos (Semana 2017, 6 de junio). Los paros no cesaron hasta que el gobierno se comprometió a invertir recursos en infraestructura y servicios hospitalarios (Vargas 2017).

En octubre, la Asociación Colombiana de Aviadores Civiles (ACDAC) convocó a los pilotos de la aerolínea Avianca a un cese de actividades que se convirtió en la huelga más larga en la historia del país. El pulso entre ACDAC y la dirección de la empresa tardó 51 días en resolverse, y le ocasionó a Avianca pérdidas cercanas a los 300.000 dólares por día. Asimismo, la Asociación Hotelera y Turística de Colombia estimó pérdidas de 13.000 millones de pesos y la Asociación Nacional de Agencias de Viajes reportó que las agencias dejaron de recibir cerca de 50 millones de dólares (Semana 2017, 22 de noviembre).

\section{COMPOSICIÓN DEL GOBIERNO}

En 2017, los bajos niveles de aprobación de los ministros así como la época preelectoral impusieron al gobierno la necesidad de recomponer el equipo de 
trabajo. Precisamente, los primeros cambios en el gabinete fueron generados por motivos electorales: Jorge Eduardo Londoño, ministro de Justicia y Derecho; Clara López, ministra de Trabajo; Aurelio Iragorri, ministro de Agricultura, y Juan Fernando Cristo, ministro del Interior, se retiraron del gabinete para participar en las elecciones de 2018 (El Espectador 2017, 5 de mayo; El Tiempo 2017, 22 de abril). El relevo en la cartera del Interior representó para el gobierno una pérdida importante. Cristo desempeñó un papel clave en el trámite de las iniciativas relacionadas con el Acuerdo de Paz en el Congreso (Semana 2017, 6 de mayo). El presidente designó al entonces viceministro del interior, Guillermo Rivera Flórez, como titular de esta cartera (Presidencia 2017, 25 de mayo).

Tabla 2. Gabinete ministerial

\begin{tabular}{|c|c|c|c|}
\hline MINISTERIO & NoMbre & PARTIDO & REGIÓN \\
\hline \multirow[t]{2}{*}{ Agricultura } & Aurelio Iragorri & $\mathrm{La} \mathrm{U}$ & Cauca \\
\hline & $\begin{array}{l}\text { Juan Guillermo } \\
\text { Zuluaga }\end{array}$ & La U & Meta \\
\hline $\begin{array}{l}\text { Ambiente y Desarrollo } \\
\text { Sostenible }\end{array}$ & Luis Gilberto Murillo & $\begin{array}{l}\text { Cambio } \\
\text { Radical }\end{array}$ & Choco \\
\hline \multirow[t]{2}{*}{$\begin{array}{l}\text { Comercio, Industria y } \\
\text { Turismo }\end{array}$} & María Lacouture & La U & Magdalena \\
\hline & $\begin{array}{l}\text { María Lorena } \\
\text { Gutiérrez }\end{array}$ & Independiente & Bogotá \\
\hline Cultura & María Garcés & Conservador & $\begin{array}{l}\text { Valle del } \\
\text { Cauca }\end{array}$ \\
\hline Defensa Nacional & Luis Carlos Villegas & Liberal & Risaralda \\
\hline Educación & Yaneth Giha & La U & Atlántico \\
\hline $\begin{array}{l}\text { Hacienda y Crédito } \\
\text { Público }\end{array}$ & Mauricio Cárdenas & Conservador & Bogotá \\
\hline \multirow[t]{2}{*}{ Interior } & Juan Fernando Cristo & Liberal & $\begin{array}{l}\text { Norte de } \\
\text { Santander }\end{array}$ \\
\hline & $\begin{array}{l}\text { Guillermo Rivera } \\
\text { Flórez }\end{array}$ & Liberal & Putumayo \\
\hline \multirow[t]{2}{*}{ Justicia y Derecho } & $\begin{array}{l}\text { Jorge Eduardo } \\
\text { Londoño }\end{array}$ & Alianza verde & Boyacá \\
\hline & Enrique Gil Botero & Conservador & Antioquia \\
\hline Minas y Energía & Germán Arce Zapata & Conservador & Valle \\
\hline Relaciones Exteriores & María Ángela Holguín & Independiente & Bogotá \\
\hline Salud y Protección Social & Alejandro Gaviria & Independiente & Antioquia \\
\hline $\begin{array}{l}\text { Tecnologías de } \\
\text { Información y las } \\
\text { Comunicaciones }\end{array}$ & David Luna & Liberal & Bogotá \\
\hline
\end{tabular}




\begin{tabular}{llll}
\hline \multicolumn{1}{c}{ Ministerio } & \multicolumn{1}{c}{ NombRe } & \multicolumn{1}{c}{ PARTido } & \multicolumn{1}{c}{ ReGión } \\
\hline \multirow{2}{*}{ Trabajo } & Clara López & $\begin{array}{l}\text { Polo } \\
\text { Democrático }\end{array}$ & Bogotá \\
& Griselda Restrepo & Liberal & Valle \\
\multirow{2}{*}{ Transporte } & Jorge Eduardo Rojas & La U & Caldas \\
& Germán Cardona & Liberal & Caldas \\
Vivienda, Ciudad y & Elsa Nogera & CR & Atlántico \\
Territorio & Jaime Pumarejo & CR & Atlántico \\
& Camilo Sánchez Ortega & Liberal & Bogotá \\
\hline
\end{tabular}

Fuente: elaboración propia

A mediados de julio, todos los ministros renunciaron a sus cargos, lo que permitió al gobierno reconstituir el gabinete para el último año de administración (Semana 2017, 19 de julio). En el mes de agosto, el gobierno anunció cuatro nuevos nombramientos. En el Ministerio de Comercio, el presidente nombró a María Lorena Gutiérrez, quien había trabajado con la administración como Consejera Presidencial para el Buen Gobierno y Secretaria General de la Presidencia (La Silla Vacía 2017). Germán Cardona fue designado como ministro de Transporte, posición que ya había ocupado en 2010. Como ministro de Agricultura, el presidente nombró a Juan Zuluaga, que era director de Seguimiento y Evaluación de los Acuerdos de Paz de la Presidencia (Semana 2017, 3 de octubre). Finalmente, en el Ministerio de Vivienda, Ciudad y Territorio fue designado Jaime Pumarejo. Sin embargo, en octubre, Pumarejo renunció debido a la ruptura de su partido, Cambio Radical, con el gobierno. Camilo Sánchez, Alto Consejero Presidencial para las Regiones, fue designado como ministro de Vivienda (Semana 2017, 10 de octubre).

Al cerrar el año, el gabinete ministerial lo conformaban cinco mujeres (31\%) y once hombres (69\%). En general, los cambios pretendieron rodear al gobierno de funcionarios afines a la administración y representar a los partidos de la coalición gobernante. Así, el Partido Liberal y el Partido de la U concentraron la mayoría de las posiciones en el gabinete, especialmente después de la fractura con Cambio Radical. El resto de los cargos quedó en manos de miembros del Partido Conservador e independientes.

\section{PRODUCCIÓN LEGISLATIVA: EL FRACASO DE LA APROBACIÓN EXPEDITA}

Durante 2017 las labores legislativas se concentraron en la implementación del Acuerdo de Paz. Como se mencionó anteriormente, la gestión del gobierno Santos en el Congreso fue entorpecida por la dinámica preelectoral, la falta 
de capital político de la administración y los altos niveles de polarización en el Congreso. Durante este año, el gobierno radicó 24 propuestas relacionadas con el acuerdo en el Legislativo. Solo nueve de estas fueron aprobadas (OIAP 2018). Durante el primer semestre legislativo, el Congreso tramitó normas relacionadas con la participación política de la FARC, así como la seguridad jurídica de la nueva agrupación.

Tabla 3. Normatividad aprobada durante el fast track

\begin{tabular}{|c|c|c|}
\hline Norma & Asunto & $\begin{array}{c}\text { RELACIÓN CON EL } \\
\text { ACUERDO DE PAZ }\end{array}$ \\
\hline $\begin{array}{l}\text { Ley } 1830 \text { de } 2017 \text {. Por medio de la } \\
\text { cual se adiciona un artículo transi- } \\
\text { torio a la Ley } 5 \text { de } 1992\end{array}$ & $\begin{array}{l}\text { Autoriza tres voceros en la } \\
\text { Cámara y tres en el Senado } \\
\text { para hacer el seguimiento } \\
\text { a la implementación del } \\
\text { acuerdo }\end{array}$ & $\begin{array}{l}\text { Punto } 3 \text { - Fin del } \\
\text { conflicto }\end{array}$ \\
\hline $\begin{array}{l}\text { Ley } 1865 \text { de } 2017 \text {. Por medio de la } \\
\text { cual se exceptúa a la Unidad Na- } \\
\text { cional de Protección (UNP) de lo } \\
\text { dispuesto en el artículo } 92 \text { de la Ley } \\
617 \text { de } 2000\end{array}$ & $\begin{array}{l}\text { Autoriza ampliar planta de } \\
\text { personal de la UNP, permi- } \\
\text { te a los desmovilizados ser } \\
\text { formados como escoltas, } \\
\text { ingresar a la planta de la } \\
\text { UNP. Autoriza seguridad a } \\
\text { desmovilizados de las Farc }\end{array}$ & $\begin{array}{l}\text { Punto } 3 \text { - Fin del } \\
\text { conflicto }\end{array}$ \\
\hline $\begin{array}{l}\text { Proyecto de Ley Estatutaria No. } 03 \\
\text { de 2017. Por medio de la cual se } \\
\text { adopta el Estatuto de la Oposición } \\
\text { Política y algunos derechos a las } \\
\text { agrupaciones políticas indepen- } \\
\text { dientes }\end{array}$ & $\begin{array}{l}\text { El Estatuto de la Oposición } \\
\text { provee el marco general } \\
\text { para el ejercicio del derecho } \\
\text { a la oposición. También } \\
\text { describe mecanismos para } \\
\text { su protección }\end{array}$ & $\begin{array}{l}\text { Punto } 2 \text { - Partici- } \\
\text { pación política }\end{array}$ \\
\hline $\begin{array}{l}\text { Proyecto de ley Estatutaria de la } \\
\text { Administración de Justicia en la Ju- } \\
\text { risdicción Especial para la Paz (JEP) }\end{array}$ & $\begin{array}{l}\text { Desarrolla el componente } \\
\text { de Justicia estableciendo } \\
\text { sus principios; su compe- } \\
\text { tencia material, personal y } \\
\text { temporal; su estructura; las } \\
\text { funciones del Tribunal para } \\
\text { La Paz y la de las tres salas } \\
\text { que componen la JEP }\end{array}$ & $\begin{array}{l}\text { Punto } 5 \text { - Vícti- } \\
\text { mas }\end{array}$ \\
\hline $\begin{array}{l}\text { Acto legislativo } 01 \text { de } 2017 \text {. Por } \\
\text { medio del cual se crea un título } \\
\text { de disposiciones transitorias de la } \\
\text { Constitución para la terminación } \\
\text { del conflicto y la construcción de } \\
\text { una paz estable y duradera }\end{array}$ & $\begin{array}{l}\text { Creó el Sistema Integral de } \\
\text { Verdad, Justicia, Reparación } \\
\text { y No Repetición que está } \\
\text { compuesto por Comisión } \\
\text { para el Esclarecimiento de } \\
\text { la verdad, Unidad para la } \\
\text { búsqueda de personas des- } \\
\text { aparecidas y Jurisdicción } \\
\text { Especial para la Paz (JEP) }\end{array}$ & $\begin{array}{l}\text { Punto } 5 \text { - Vícti- } \\
\text { mas }\end{array}$ \\
\hline
\end{tabular}


Acto legislativo 02 de 2017. Por medio del cual se adiciona un artículo transitorio a la Constitución con el propósito de dar estabilidad y seguridad jurídica al Acuerdo Final

Acto legislativo 03 de 2017. Por medio del cual se regula parcialmente el componente de reincorporación política del Acuerdo Final para la terminación del conflicto y la construcción de una paz estable y duradera.

Acto legislativo 04 de 2017. Por el cual se adiciona el artículo 361 de la Constitución Política

Acto Legislativo 05 de 2017. Por medio del cual se dictan disposiciones para asegurar el monopolio legítimo de la fuerza y del uso de las armas por parte del Estado
Este acto brinda seguridad jurídica al acuerdo y obliga a las próximas administraciones a preservar y cumplir los contenidos del acuerdo.

Establece garantías para la reincorporación política de la FARC, creación del partido político para las FARC con personería jurídica y garantías legales.

Modifica el sistema general de regalías para proveer fondos a proyectos para la implementación del Acuerdo de Paz y la amnistía

Reitera el monopolio legítimo de la fuerza por el Estado; prohíbe la creación, Punto 3 - Fin del promoción, financiación y otras formas de respaldo a grupos armados ilegales
Punto 3 - Fin del conflicto

Punto 6 - Implementación

Fuente: Fundación Paz y Reconciliación (2018) y Congreso de la República de Colombia (n.d.)

Los debates en el Congreso en la segunda parte del año se tornaron más complejos debido a los cambios en el procedimiento de aprobación expedita adoptados por la Corte Constitucional (Corte Constitucional 2017). Específicamente, la Corte eliminó la necesidad de votar las iniciativas en bloque, lo que permitió al Congreso discutir iniciativas artículo por artículo. En segundo lugar, removió el requisito del aval del gobierno para realizar cambios en los proyectos. Este último punto permitió una intervención más directa por parte de los representantes durante los debates del fast track (El Tiempo 2017, 12 de junio). Los cambios generaron debates más intensos y complejos, lo que llevó a rupturas entre las alianzas partidistas. Esto redujo las oportunidades para encontrar consensos que posibilitaran la aprobación de varios proyectos (Verdad Abierta 2017, 2 de diciembre).

El periodo legislativo especial concluyó a finales de noviembre con un balance regular. En relación con el tema agrario, el gobierno radicó cinco proyectos de ley. Solo el de Regalías para el Postconflicto fue aprobado (Chaverra 2017). De la misma manera, los debates relacionados con el proyecto de la reforma política y electoral y el proyecto para las circunscripciones de paz evidenciaron diferencias 
entre las bancadas en el Congreso y la ya mencionada falta de capacidad política por parte de la administración (Semana 2017, 2 de diciembre). Un ejemplo del extremo enfrentamiento entre Ejecutivo y Legislativo fue el debate para la aprobación de las circunscripciones de paz. El proyecto de ley que se debatió en el Senado obtuvo cincuenta votos a favor y siete en contra. Para el Senado, el número de votos no constituye una mayoría absoluta ya que esta colectividad está compuesta por 102 senadores. Sin embargo, para el gobierno los votos obtenidos sí representaron una mayoría, ya que en el momento de la votación tres senadores se encontraban suspendidos. Así, el gobierno consideró el proyecto aprobado pero el Senado no (Uprimny 2017). Aunque la administración Santos agotó todos los recursos legales, al final la decisión del Senado se mantuvo y el proyecto fue rechazado (Espitia 2018).

\section{ENTORNO INTERNACIONAL}

Durante 2017 dos actores externos incidieron de manera directa en la gestión de la administración Santos: Estados Unidos y Venezuela. Esta sección repasa la evolución en las relaciones bilaterales con estos países.

\section{Estados Unidos y Colombia: las drogas y el apoyo a la paz}

El inicio de la administración de Donald Trump alteró la relativa calma que caracterizó las relaciones entre Estados Unidos y Colombia durante los últimos años. Para el gobierno colombiano, contar con el respaldo de la nueva administración de Estados Unidos era importante para asegurar la continuidad de la ayuda económica y militar provenientes de este país. Aunque los temas principales de la agenda bilateral no cambiaron sustancialmente, la administración Trump sí alteró su orden de prioridades. Al igual que anteriores administraciones del Partido Republicano, bajo el gobierno de Trump la lucha antinarcóticos y el papel de los actores ilegales en el tráfico de drogas ganaron mayor relevancia que el apoyo a las políticas de paz y los derechos humanos. Así, la primera visita del presidente Santos a la Casa Blanca en mayo buscó calibrar el apoyo de Estados Unidos al proceso de paz. El balance del primer encuentro entre los mandatarios fue positivo; el presidente Trump y varios miembros del Congreso elogiaron la gestión de Santos (Semana 2017, 18 de mayo).

Con respecto a los recursos para la paz, el 2017 dejó dos noticias positivas para Colombia. Primero, el Congreso de Estados Unidos aprobó el paquete de ayuda requerido durante 2016 por la administración Obama, que otorgó al país 450 millones de dólares. Esta cifra incluye 391 millones en ayuda y dineros provenientes de programas antinarcóticos y otras iniciativas. Segundo, Colombia salió beneficiada durante la negociación para definir el presupuesto del año 2018: contrariando los deseos de Trump, el Congreso norteamericano no recortó los montos de ayuda exterior. Esto favoreció a Colombia, pues aseguró 
recursos importantes para la implementación de la paz (Gaytan y Naylor 2017; Orozco 2017).

El otro punto que dominó la agenda bilateral fue la lucha antinarcóticos. El tema venía generando tensiones desde 2015, cuando Colombia suspendió la fumigación aérea de cultivos ilícitos (Forero 2015). En esa oportunidad, el embajador de Estados Unidos Kevin Whitaker mencionó su preocupación por el impacto de la nueva estrategia (El Espectador 2016, septiembre 7). Una vez conocido el mencionado aumento en la producción de cocaína, la presión desde la Casa Blanca se hizo más contundente. Durante su visita a Colombia, el vicepresidente de Estados Unidos Mike Pence reiteró la preocupación por el incremento de los cultivos ilícitos (El Espectador 2017, 14 de agosto). Posteriormente, en un memorando al Secretario de Estado, el presidente Trump expresó que había considerado designar a Colombia como país no cooperante en la lucha antinarcóticos (Asmann 2017). De ser así, Colombia perdería parte de la ayuda de Estados Unidos. El gobierno de Santos defendió los logros de sus políticas antinarcóticos, esperando neutralizar la percepción generalizada entre sectores políticos de Estados Unidos sobre el la falta de cumplimiento de los acuerdos por parte de las FARC (Clavel 2017; Peña 2017).

Es claro que el tema antinarcóticos cobrará importancia en el futuro. La desconfianza hacia las FARC (aún en la lista de organizaciones terroristas del Departamento de Estado), y por extensión al Acuerdo de Paz, puede costarle a Colombia recursos necesarios para su implementación.

\section{La crisis en Venezuela}

La crisis venezolana generó en 2017 la ola migratoria más grande de la historia colombiana. ${ }^{3}$ En este año la migración desde ese país aumentó en un $62 \%$ (Oficina de Migraciones 2018). El flujo de migrantes generó presiones sociales y económicas en las regiones limítrofes y en las principales ciudades del país que demandaron recursos importantes de la administración Santos. La incapacidad para atender a la crisis de refugiados deterioró la salud pública e incrementó actividades ilegales como el narcotráfico y crimen organizado (El Tiempo 2017, 30 de marzo). Adicionalmente, la población venezolana impactó la competencia laboral: la mano de obra venezolana (a veces sin documentos) ha empezado a desplazar la colombiana en varias ciudades (Vanguardia 2017, 27 de diciembre).

A nivel diplomático, las relaciones bilaterales cambiaron durante 2017. Si bien la administración venezolana jugó un papel positivo durante el inicio de las negociaciones con las FARC en 2012, durante 2017 las declaraciones del presidente Nicolás Maduro pusieron a prueba la diplomacia colombiana. La ministra de

La crisis venezolana no es el objeto de este artículo, para una revisión de este tema se sugiere Cannon y Brown (2016). 
Relaciones Exteriores, María Angela Holguín, enfrentó cuidadosamente la crisis migratoria y los fuertes pronunciamientos del presidente Maduro. En junio, el gobierno anunció que el embajador colombiano no regresaría a Venezuela (El Tiempo 2017, 31 de julio). En julio, Colombia firmó la Declaración de Lima, en la cual varios países de la región declararon que Venezuela había dejado de ser una democracia debido a los problemas presentados en las elecciones en ese país (BBC 2017, 9 de agosto). En agosto, el presidente Santos endureció su postura a través de una columna en la que aseveró que la crisis en Venezuela representaba un problema serio para Colombia (El Tiempo 2017, 10 de noviembre; Semana 2017, 14 de agosto).

La crisis fronteriza plantea serios desafíos: por un lado, satisfacer las demandas de los migrantes requerirá recursos que el gobierno requiere para las políticas relacionadas con la implementación de la paz. Por otro lado, las necesidades económicas extremas generan un mercado de personas disponibles para engrosar los ejércitos ilegales, así como para la explotación de menores y mujeres. El Estado tendrá que invertir recursos en programas para atender y prevenir estos problemas.

\section{REFLEXIONES FINALES}

Durante 2017 el gobierno colombiano enfrentó altos niveles de polarización política, así como la crisis de seguridad generada por la recomposición del poder territorial. Estos eventos obstaculizaron el cumplimiento del Acuerdo de Paz. Por este motivo, la incertidumbre sobre su futuro fue la constante del año. Los avances y deficiencias en la implementación cobran relevancia al considerar que 2018 es año de elecciones presidenciales y legislativas. Sin duda, los eventos de 2017 impactarán la agenda de la nueva administración presidencial de varias maneras.

Primero, la incertidumbre que caracterizó a 2017 generó desconfianza entre los excombatientes. Las demoras y problemas dejaron a los militantes en una posición bastante precaria, lo que llevó a muchos individuos a reintegrarse al conflicto. Si bien esto ha sucedido en otros procesos de desmovilización, para salvar el proceso de paz la administración deberá enviar señales contundentes sobre su voluntad de fortalecer la implementación. Empero, a juzgar por la polarización de 2017 y el limitado apoyo de los partidos políticos al Acuerdo de Paz, es improbable que a la nueva administración tome dicha decisión sin los incentivos correctos. Así, la presión para continuar con la implementación del acuerdo tendrá que surgir de la sociedad civil y la comunidad internacional. Si bien todo indica que Estados Unidos no va a ser parte de ese esfuerzo, otros países y diversas organizaciones internacionales podrían jugar un papel importante.

Por otro lado, la incertidumbre impactó también las poblaciones de los territorios más golpeados por el conflicto armado y la pobreza. Mientras que hubo algunos 
avances en torno a los PDETs y otras inversiones, la población rural aún espera que se cumpla lo pactado en el acuerdo. La nueva administración tendrá que generar programas de desarrollo que atiendan a estos sectores, de lo contrario los paros cívicos y demandas sociales incrementarán. La falta de presencia estatal en varios territorios debe ser atendida por el gobierno nacional y de la misma manera ocurre con el tema de la apertura política para las víctimas. Debido al poco capital político de la administración Santos, esta tarea le corresponderá al nuevo gobierno y al Congreso. Esto es más probable si sectores de la opinión pública nacional e internacional trabajan conjuntamente para poner a las víctimas en la agenda nacional.

Lamentablemente la alarmante situación de los defensores de derechos humanos y líderes sociales seguirá siendo una constante en 2018. Si no se formula una sanción legal y social contundente en este tema, las violaciones a los derechos humanos continuarán. La experiencia sugiere que la presión de actores internacionales así como de organizaciones sociales es clave para detenerlas. Asimismo, la inseguridad creada por los actores relacionados con el tráfico ilícito de drogas y minerales será un problema para el nuevo gobierno. Los hechos de 2017 sugieren que este tema es más complejo de lo que se pensaba ya que hay múltiples actores interesados en controlar las zonas con presencia de estos recursos. La crisis de seguridad también demuestra que la solución a este problema debe ser integral y no solo militar. Lejos de seguir recurriendo a esquemas de seguridad, incrementar la presencia de las autoridades civiles y militares en las zonas que históricamente han sufrido el conflicto armado es el principal desafío de Colombia en 2018. Si 2017 fue el año de la incertidumbre, está por verse si la nueva administración y la sociedad colombiana deciden corregir el curso y fortalecer la implementación del acuerdo con las FARC para evitar así un recrudecimiento de la violencia en el país.

\section{REFERENCIAS}

Abril, Natalia y Luisa Uribe. 2018. “¿Qué pasó con los programas de desarrollo en territorios del conflicto?" Recuperado el 20 de mayo de 2018 de https: / / colombia2020.elespectador.com/opinion/que-paso-con-los-programas-de-desarrollo-en-territorios-del-conflicto

Alta Consejería Presidencial para el Postconflicto. 2017. “La sustitución voluntaria de cultivos de uso ilícito avanza en Colombia." Recuperado el 29 de marzo de 2018 de http:/ / www.posconflicto.gov.co/sala-prensa/noticias/2017/Paginas/20171027-La-sustitucion-voluntaria-de-cultivos-de-uso-ilicito-avanza-en-Colombia.aspx

Alto Comisionado para la Paz. 2016. Acuerdo Final. Recuperado el 6 de abril de 2018 de http:/ / www.altocomisionadoparalapaz.gov.co/procesos-y-conversaciones/Documentos\%20compartidos/24-11-2016NuevoAcuerdoFinal.pdf

Álvarez, Eduardo y Daniel Pardo. 2017. Entornos y riesgos de las Zonas Veredales y los Puntos Transitorios de Normalización. Recuperado el 7 de abril de 2018 de http:/ / cdn.ideaspaz. org/media/website/document/588d509ecd0be.pdf

ANDI. 2017. 2017: un mal año para la industria. Recuperado el 8 de marzo de 2018 de http:/ / www.andi.com.co/Uploads/Informe\%20EOIC\%20Diciembre\%202017.pdf 
Asmann, Parker. 2017. “EEUU amenaza con calificar a Colombia de incumplimiento en iniciativas antinarcóticos." Recuperado el 23 de marzo de 2018 de https:/ / es.insightcrime. org/noticias/noticias-del-dia/eeuu-amenaza-calificar-colombia-incumplimiento-iniciativas-antinarcoticos/\#

Banco de la Republica de Colombia. 2018. Informe sobre Inflación 2017. Recuperado el 27 de febrero de 2018 de http:/ / www.banrep.gov.co/sites/default/files/publicaciones/archivos/informe_sobre_inflacion_diciembre_2017.pdf

BBC. 2017, 9 de agosto. "Cancilleres de 12 países de América y el Caribe suscriben en la 'Declaración de Lima' que Venezuela 'no es una democracia'." Recuperado el 22 de marzo de 2018 de http:/ / www.bbc.com/mundo/40871449

Beittel, June. 2017. Colombia: Background and U.S. Relations. Recuperado el 2 de marzo de 2018 de https:/ / fas.org/sgp/crs/row/R43813.pdf

Cannon, Barry y John Brown. 2017. "Venezuela 2016: El año de vivir peligrosamente." Revista Ciencia Política 37 (2): 613-633.

CEPAL. 2017. "Economías de América Latina y el Caribe tendrán moderada recuperación en 2018 y crecerán 2,2\%." Recuperado el 28 de febrero de 2018 de https://www.cepal. org/es/comunicados/economias-america-latina-caribe-tendran-moderada-recuperacion-2018-creceran-22

CERAC. 2017, 1 de diciembre. "Se deteriora el cumplimiento del cese el fuego con el ELN en su segundo mes." Recuperado el 6 de abril de 2018 de http:/ / blog.cerac.org.co/monitor-del-cese-el-fuego-bilateral-y-temporal-con-el-eln-2

CERAC. 2017, 30 de junio. "Monitor del Cese el Fuego Bilateral y de Hostilidades." Recuperado el 6 de abril de 2018 de http:/ /blog.cerac.org.co/monitor-del-cese-el-fuego-bilateral-y-de-hostilidades-final

Chaverra, Fredy. 2017. "El fracaso de la reforma rural en el Congreso." Recuperado el 14 de marzo de 2018 de https://www.las2orillas.co/el-fracaso-de-la-reforma-rural-integral-en-el-congreso/

Clavel, Tristán. 2017. "Audiencia de Congreso de Estados Unidos pone de manifiesto tensiones por acuerdo de paz en Colombia." Recuperado el 6 de abril de 2018 de https:/ / es.insightcrime.org/noticias/analisis/audiencia-congreso-estados-unidos-pone-manifiesto-tensiones-acuerdo-paz-colombia/

CNN en español. 2017, 5 de diciembre. “¿En qué queda el proceso de paz con el ELN tras la renuncia del jefe negociador del Gobierno?" Recuperado el 3 de abril de 2018 de http:/ / cnnespanol.cnn.com/2017/12/05/en-que-queda-el-proceso-de-paz-con-el-eln-trasla-renuncia-del-jefe-negociador-del-gobierno/

Congreso de la República de Colombia. n.d. Proyectos de Ley Fast Track. Recuperado el 10 de enero de 2018 de http:/ / www.senado.gov.co/az-legislativo/proyectos-de-ley

Corporación Nuevo Arcoiris. 2017. "Las ocho Bacrim que hoy amenazan la seguridad de Colombia." Recuperado el 3 de febrero de 2018 de https://www.arcoiris.com. co/2017/07/las-ocho-bacrim-que-hoy-amenazan-la-seguridad-de-colombia/

Corte Constitucional de Colombia. 2017. Sentencia 332-17. Recuperado el 20 de marzo de 2018 de http:/ / www.corteconstitucional.gov.co/relatoria/2017/C-332-17.htm

DANE. 2017a, diciembre. Mercado Laboral Nacional Diciembre 2017. Recuperado el 27 de febrero de 2018 de https://www.dane.gov.co/files/investigaciones/boletines/ech/ech/ pres_web_empleo_rueda_prensa_dic_17.pdf

DANE. 2017b, 11 de agosto. "Pobreza Monetaria 2016: Chocó." Recuperado el 2 de marzo de 2018 de https://www.dane.gov.co/files/investigaciones/condiciones_vida/pobreza/2016/Choco_Pobreza_2016.pdf

DANE. 2018. Boletín técnico Producto Interno Bruto. Cuarto trimestre de 2017. Recuperado el 14 de febrero de 2018 http://www.dane.gov.co/files/investigaciones/boletines/pib/ bol_PIB_IVtrim17_oferta_demanda.pdf

De Justicia. 2017. "Estado de Derecho, Política de Drogas." Recuperado el 14 de marzo de 2018 de https:/ / www.dejusticia.org/column/hoy-lo-urgente-es-la-vida-y-no-la-erradicacion-de-la-coca-cualquier-precio/ 
El Colombiano. 2017, 11 de diciembre. "Nuevo plan de seguridad para 67 municipios del país." Recuperado el 2 de marzo del 2018. http:/ / www.elcolombiano.com/colombia / plan-de-seguridad-para-colombia-EM7842701

El Espectador. 2016, 7 de septiembre. "El glifosato es eficaz y seguro." Recuperado el 22 de marzo de 2018. https://www.elespectador.com/noticias/judicial/el-glifosato-eficaz-y-seguro-embajador-de-eeuu-colombia-articulo-653484

El Espectador. 2017, 14 de agosto. "Esto tiene que terminar pronto: Pence." Recuperado el 22 de marzo de 2018 https://www.elespectador.com/noticias/el-mundo/esto-tiene-que-terminar-pronto-pence-exige-colombia-atajar-aumento-en-cultivos-ilicitos-articulo-708093

El Espectador. 2017, 17 de diciembre. "Asesinatos de líderes son por líos de faldas." Recuperado el 3 de marzo de 2018 de https:/ /www.elespectador.com/noticias/politica/ asesinatos-de-lideres-son-por-lios-de-faldas-ministro-de-defensa-articulo-728893

El Espectador. 2017, 20 de julio. "Listo decreto que agiliza amnistías e indultos para guerrilleros de las FARC." Recuperado el 27 de febrero de 2018 de https:/ / www.elespectador.com/noticias/paz/listo-decreto-que-agiliza-amnistias-e-indultos-para-guerrilleros-de-las-farc-articulo-704203

El Espectador. 2017, 25 de julio. "Los hechos claves para entender el escándalo de Odebrecht." Recuperado el 29 de marzo de 2018 de https:/ / www.elespectador.com/noticias/judicial/los-hechos-claves-para-entender-el-escandalo-de-odebrecht-articulo-704916

El Espectador. 2017, 5 de mayo. "Clara López renuncia al Ministerio del Trabajo." Recuperado el 3 de marzo de 2018 de: https:/ / www.elespectador.com/economia/clara-lopez-renuncia-al-ministerio-del-trabajo-articulo-692408

El Espectador. 2017, 16 de noviembre. “¿Renegociando la JEP?” Recuperado el 20 de marzo de 2018 de https:/ / colombia2020.elespectador.com/jep/renegociando-la-jep

El Espectador. 2017, 3 de noviembre. "La erradicación forzosa no es desarrollo, es una medida represiva: ONU." Recuperado el 20 de marzo de 2018 de https://www.elespectador. $\mathrm{com} /$ noticias/paz/la-erradicacion-forzosa-no-es-desarrollo-es-una-medida-represiva-onu-articulo-721355

El Espectador. 2017, 13 de septiembre. "Según campesinos, el gobierno incumplió en acuerdo de sustitución de cultivos ilícitos." Recuperado el 21 de marzo de 2018 de $h t t p s: / / w w w$. elespectador.com/noticias/paz/segun-campesinos-gobierno-incumplio-en-acuerdo-de-sustitucion-de-cultivos-ilicitos-articulo-713117

El Espectador. 2018, 18 de febrero. "Líderes de sustitución de coca, objetivo del narcotráfico." Recuperado el 2 de marzo de 2018 de https:/ /colombia2020.elespectador.com/territorio/lideres-de-sustitucion-de-coca-objetivo-del-narcotrafico

El País. 2017, 10 de octubre. “¿Qué hay detrás del 'divorcio' de Cambio Radical del Gobierno?" Recuperado el 17 de mayo de 2018 de http:/ / www.elpais.com.co/politica/quehay-detras-del-divorcio-de-cambio-radical-del-gobierno.html Mayo 22

El Tiempo. 2017, 22 de abril. "Estos son los altos funcionarios que alistan maletas para 2018." Recuperado el 20 de marzo de 2018 de http://www.eltiempo.com/politica/partidos-politicos / ministros-que-renunciarian-para-aspirar-en-elecciones-de-2018-80636

El Tiempo. 2017, 9 de enero. “Gobierno pretende acabar con 100 mil hectáreas de coca en el 2017." Recuperado el 28 de marzo de 2018 de http://www.eltiempo.com/justicia/ cortes/plan-para-erradicar-cultivos-de-coca-en-colombia-en-2017-45814

El Tiempo. 2017, 31 de julio. "El embajador de Colombia 'no volverá por ahora' a Venezuela." Recuperado el 22 de marzo de 2018 de http://www.eltiempo.com/politica/embajador-de-colombia-en-venezuela-no-volvera-a-ese-pais-115034

El Tiempo. 2017, 12 de junio. "Cinco razones para permitir que el Congreso cambie leyes de paz." Recuperado el 2 de marzo de 2018 de http:/ /www.eltiempo.com/justicia/ cortes / fast-track-los-argumentos-de-la-corte-constitucional-en-fallo-que-le-permitioal-congreso-modificar-las-leyes-de-paz-96916

El Tiempo. 2017, 30 de marzo. "Atracos, el lado oscuro del éxodo de los venezolanos." Recuperado el 22 de marzo de 2018 de http://www.eltiempo.com/justicia/delitos/ 
llegada-de-venezolanos-ha-generado-inseguridad-en-santander-y-norte-de-santander-72842

El Tiempo. 2017, 10 de mayo. “Una vez más, Chocó le reclama al Gobierno Nacional." Recuperado el 27 de febrero de 2018 de http://www.eltiempo.com/colombia/otras-ciudades/ paro-civico-en-choco-y-2017-86500

El Tiempo. 2017, 10 de noviembre. "Santos dice que su 'peor pesadilla' es Venezuela." Recuperado el 2 de marzo de 2018 de http://www.eltiempo.com/politica/gobierno/ juan-manuel-santos-dice-que-venezuela-es-su-peor-pesadilla- 149890

El Tiempo. 2017, 25 de octubre. "Hay entre 500 y 800 disidentes de las Farc." Recuperado el 30 de marzo de 2018 de $h$ ttp://www.eltiempo.com/politica/proceso-de-paz/defensor-del-pueblocarlos-negret-dice-que-hay-800-disidentes-de-las-farc-144882

El Tiempo. 2017, 27 de septiembre. “Orden del presidente es arreciar las operaciones sin contemplación." Recuperado el 4 de abril de 2018 de http://www.eltiempo.com/justicia/conflicto-y-narcotrafico/vicepresidente-lanza-centro-de-operaciones-en-guaviare- 135268

El Tiempo. 2018, 20 de marzo. “ONU, 'extremadamente preocupada' por violencia contra líderes." Recuperado el 13 de abril de 2018 de http://www.eltiempo.com/justicia/ conflicto-y-narcotrafico/onu-presenta-cifras-sobre-ataques-y-asesinatos-a-lideres-sociales-en-2017-195958

Espitia, Jeaneth. 2018. "Niegan al gobierno acción de cumplimiento sobre 16 curules en Cámara." Recuperado el 22 de mayo de 2018 de http:/ / www.senado.gov.co/component/ k2/item/27673-niegan-al-gobierno-accion-de-cumplimiento-sobre-16-curules-en-camara?tmpl=component\&print $=1$,

Forero, Juan. 2015. "Colombia Takes U-Turn on Drug Policy." Recuperado el 4 de abril de 2018 de https://www.wsj.com/articles/colombia-takes-u-turn-on-drug-policy-1431650471

Fundación Paz y Reconciliación. 2017. Terminó la guerra, el postconflicto está en riesgo. Recuperado el 10 de febrero de 2018 de http:/ / www.pares.com.co/carrusel/termino-la-guerrael-postconflicto-esta-en-riesgo-un-ano-del-acuerdo-de-paz/

Garzón, Juan y Manuela Suárez. 2018. En qué va la sustitución de cultivos ilícitos? Recuperado el 10 de febrero de 2018 de http://cdn.ideaspaz.org/media/website/document/5a905d8a0546e.pdf

Gaytan, Victoria y William Naylor. 2017. "A deep dive into the Trump cuts for Latin America." Recuperado el 10 de febrero de 2018 de https://theglobalamericans.org/2017/06/ deep-dive-trump-cuts-latin-america/

Gómez, Marisol. 2017. "El chance del ELN para dar 'el primer paso'." Recuperado el 30 de febrero de 2018 de http://www.eltiempo.com/politica/proceso-de-paz/analisis-dela-oportunidad-del-eln-con-el-cese-del-fuego-129012

González, Leonardo y Cristian Delgado. 2018. "Homicidio de defensores y defensoras de paz: una tragedia que no se detiene." Recuperado el 2 de marzo de 2018 de https:/ / co.boe1l.org/sites/default/files/20180228_ideasverdes_no6_web.pdf

Indepaz, Cinep, IEPRI, y Comisión Colombiana de Juristas. 2017. Panorama de violaciones al derecho a la vida, libertad e integridad de líderes sociales y defensores de derechos humanos en 2016 y primer semestre de 2017. Recuperado el 2 de abril de 2018 de http:/ /www.indepaz.org.co/wp-content/uploads/2017/10/PANORAMA-DE-VIOLACIONES.pdf

Jiménez, Juan C. 2017. “Un complejo balance: el ELN en 2017." Recuperado el 10 de enero de 2018 de "https://drive.google.com/file/d/1t3CtTLl7yzQs5xqtwNi6VAx0zkx7zz1s/view

Junieles, Irina. 2017. "Retos y Oportunidades para la transformación del campo." Recuperado el 18 de mayo de 2018 de http:/ /lasillavacia.com/silla-llena/red-rural/historia/ paz-para-transformacion-del-campo-planes-de-desarrollo-con-enfoque Mayo 20

Krock Institute. 2017. Informe sobre el estado efectivo de implementación del Acuerdo de Paz en Colombia. Recuperado el 10 de enero de 2018 de https:/ / kroc.nd.edu/assets/257593/ informe_kroc.pdf 
La Silla Vacía. 2017. "María Lorena Gutiérrez Botero." Recuperado el 20 de diciembre de 2018 de http:/ /lasillavacia.com/quienesquien/perfilquien/maria-lorena-gutierrez-botero

León, Juanita. 2017. "Las diez conclusiones demoledoras de la Gallup." Recuperado el 10 de enero de 2018 de http://lasillavacia.com/historia/las-diez-conclusiones-demoledoras-de-la-gallup-59964

Méndez, Alicia. 2017. "En los antiguos santuarios de las FARC, las disidencias asustan." Recuperado el 20 de marzo de 2018 de http:/ / www.eltiempo.com/justicia/conflicto-y-narcotrafico/disidencias-tienen-control-de-antiguas-zonas-de-control-de-las-farc-informe-145762

Ministerio de Defensa de Colombia. 2018. Logros de la Política de Defensa y Seguridad. Recuperado el 10 de enero de 2018 de https://www.mindefensa.gov.co/irj/go/km/docs/ Mindefensa/Documentos/descargas/estudios_sectoriales/info_estadistica/Logros_ Sector_Defensa.pdf

Misión de Verificación de la ONU en Colombia. 2017. "Palabras Jean Arnault, en el foro ‘La Reincorporación y Reconciliación, dimensiones de la construcción de Paz'." Recuperado el 2 de febrero de 2018 de https://colombia.unmissions.org/palabras-jean-arnault-en-el-foro-de-el-espectador- $\%$ E2\%80\%9Cla-reincorporaci $\% \mathrm{C} 3 \% \mathrm{~B} 3 \mathrm{n}$-y-reconciliaci\%C3\%B3n-dimensiones

Montilla, Paola. 2014. "Colombia hacia una restructuración del sistema político?" Revista de Ciencia Politica 34 (1): 105-124

Naciones Unidas. 2017. "Informe del Secretario General sobre la Misión de las Naciones Unidas en Colombia." Recuperado el 2 de marzo de 2018 de https://colombia.unmissions.org/sites/default/files/last_sg_report_of_the_un_mission_in_colombia_esp. pdf

Observatorio de Seguimiento a la Observación de Paz (OIAP). 2018. La Paz en deuda. Recuperado el 15 de febrero de 2018 de https:/ / oiap.co/2018/01/12/la-paz-en-deuda/

Oficina de Migraciones del Ministerio de Relaciones Exteriores de Colombia. 2018. Radiografía Migratoria. Recuperado el 2 de marzo de 2018 de http://www.migracioncolombia. gov.co/index.php/es/prensa/multimedia/6308-radiografia-de-venezolanos-en-colombia-31-12-2017

Orozco, Cecilia. 2017. "Colombia no sabe cuál Trump tendrá que enfrentar." Recuperado el 20 de enero de 2018 de https://www.elespectador.com/noticias/politica/colombia-no-sabe-cual-trump-tendra-que-enfrentar-adam-isacson-articulo-720331

OXFAM. 2017. Radiografía de la desigualdad. Recuperado el 10 de enero de 2018 de https:// d1tn3vj7xz9fdh.cloudfront.net/s3fspublic/file_attachments/radiografia_de_la_desigualdad.pdf

Peña, Edulfo. 2017. "'FARC no han cumplido en tema de drogas': embajador de Estados Unidos." Recuperado el 10 de marzo de 2018 de http://www.eltiempo.com/politica/ proceso-de-paz/embajador-de-estados-unidos-dice-que-las-farc-no-estan-cumpliendo-133982

Presidencia de la República. 2017, julio 17. "Presidente asiste este martes al lanzamiento del Programa de Desarrollo con Enfoque Territorial." Recuperado el 21 de mayo de 2018 de http://es.presidencia.gov.co/noticia/170717-Presidente-asiste-este-martes-al-lanzamiento-del-Programa-de-Desarrollo-con-Enfoque-Territorial

Presidencia de la República. 2017, 25 de mayo. "Santos designa a Guillermo Rivera Flórez como nuevo ministro." Recuperado el 10 de enero de 2018 de http:/ /es.presidencia. gov.co/noticia/170525-Presidente-Santos-acepto-la-renuncia-del-Ministro-del-Interior-Juan-Fernando-Cristo-y-anuncio-la-designacion-de-Guillermo-Rivera

Presidencia de la República. 2017, 23 de noviembre. "Aniversario Paz." Recuperado el 2 de enero de 2018 de http://es.presidencia.gov.co/noticia/171123-Aniversario-Paz-Mas-de-76-por-ciento-disminuyo-en-2017-cifra-de-soldados-heridos-en-combate-dice-Directora-del-Hospital-Militar-Central 
Programa somos Defensores. 2017. Stop Wars: Paren la guerra contra Defensores(as). Recuperado el 2 de enero de 2018 de https:/ /www.somosdefensores.org/attachments/article/148/STOP_\%20WARS_Conclusiones_y_recomendaciones_baja.pdf

Programa Somos Defensores. 2018. La piedra en el zapato. Informe 2017. Recuperado el 15 de marzo de 2018 de https://choco.org/documentos/informe-anual-2017-piedra-en-elzapato.pdf

Rodriguez-Raga, Juan. 2017. “Colombia: país del año 2016." Revista de Ciencia Politica 37 (2): 335-367.

Semana. 2017, 14 de agosto. "Relaciones entre Colombia y Venezuela, en arenas movedizas." Recuperado el 10 de febrero de 2018 de http://www.semana.com/nacion/articulo/ relaciones-diplomaticas-entre-colombia-y-venezuela/535866

Semana. 2017, 2 de diciembre. "Congresistas en deuda." Recuperado el 10 de enero de 2018 de http://www.semana.com/nacion/articulo/cincunscripciones-de-paz-congreso-dejo-pasar-los-beneficios-del-fast-track/549272

Semana. 2017, 19 de julio. "Dejamos en libertad al presidente para que estructure el equipo." Recuperado el 3 de enero de 2018 de http:/ / www.semana.com/nacion/articulo/renuncia-protocolaria-de-ministros-de-juan-manuel-santos/533100

Semana. 2017, 6 de junio. "Paro en Buenaventura llega a su fin." Recuperado el 10 de febrero de 2018 de https://www.semana.com/nacion/articulo/paro-en-buenaventura-acuerdo-entre-gobierno-y-comunidad/527628

Semana. 2017, 18 de mayo. "Colombia es un gran ejemplo para la paz en el mundo: Trump tras reunión con Santos." Recuperado el 10 de febrero de 2018 de http://www.semana. $\mathrm{com} /$ nacion/articulo/donald-trump-recibe-a-juan-manuel-santos-en-la-casa-blan$\mathrm{ca} / 525639$

Semana. 2017, 6 de mayo. "Si se va el ministro Cristo, ¿entonces quién?" Recuperado el 10 de marzo de 2018 de http://www.semana.com/nacion/articulo/juan-fernando-cristo-se-va-como-candidato-presidencial-y-deja-al-gobierno/524352

Semana. 2017, 22 de noviembre. “¿Cuánto perdió Avianca durante el paro?” Recuperado el 3 de enero de 2018 de http:/ / www.semana.com/confidenciales-semanacom/articulo/ cuanto-perdio-avianca-durante-el-paro/548218

Semana. 2017, 10 de octubre. "Cambio Radical se retira del Gobierno." Recuperado el 20 de mayo de 2018 de http://www.semana.com/nacion/articulo/luis-gilberto-murillo-y-jaime-pumajero-renuncian-al-gobierno/543451

Semana. 2017, 11 de octubre. "Corte Constitucional deja firme el piso jurídico de la paz."

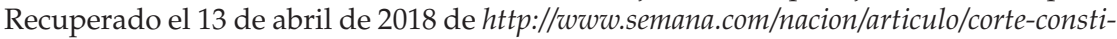
tucional-deja-firme-el-piso-juridico-de-la-paz-acto-legislativo-02-de-2017/543564

Semana. 2017, 3 de octubre. "El hombre detrás de la visita del Papa, nuevo ministro de Agricultura." Recuperado el 10 de febrero de 2018 de http:/ /www.semana.com/nacion/ articulo/juan-guillermo-zuluaga-nuevo-ministro-de-agricultura/542553

The International Crisis Group. 2017. Los grupos armados de Colombia y su disputa por el botín de la paz. Recuperado el 20 de febrero de 2018 de https://d2071andvip0wj.cloudfront.net/063-los-grupos-armados-de-colombia-y-su-disputa-spanish_1.pdf

Transparencia International. 2018. Índice de Percepción de la Corrupción 2017. Recuperado el 20 de marzo de 2018 de http://transparenciacolombia.org.co/indice-de-percepcion-dela-corrupcion-2017-corrupcion-aun-sin-solucion-de-fondo/

United Nations Office of Drug and Crime (UNODC). 2017. Colombia, Monitoreo de territorios afectados por cultivos ilícitos 2016. Recuperado el 10 de febrero de 2018 de https:/ / www. unodc.org/documents/colombia/2017/julio/CENSO_2017_WEB_baja.pdf

United States Department of State. 2017. International Narcotics Control Strategy Report. Recuperado el 10 de febrero de 2018 de https://www.state.gov/documents/organization/268025.pdf

Uprimny, Rodrigo. 2017. "Fueron aprobadas las circunscripciones especiales?" Recuperado el 10 de enero de 2018 de http:/ / lasillavacia.com/blogs/mi-plebi-si-tio/fueron-aprobadas-las-circunscripciones-especiales-63762 
Vanguardia. 2017, 27 de diciembre. "Mano de obra colombiana, desplazada por venezolana." Recuperado el 10 de febrero de 2018 de http://www.vanguardia.com/colombia/419809-mano-de-obra-colombiana-desplazada-por-venezolana

Vargas, Hans. 2017, 6 de junio. "Así se llegó al acuerdo para levantar el paro en Buenaventura." Recuperado el 10 de enero de 2018 de https:/ / www.elespectador.com/economia/asi-se-llego-al-acuerdo-para-levantar-el-paro-en-buenaventura-articulo-697205

Verdad Abierta. 2017, 2 de diciembre. "El duro paso de la paz por el Congreso." Recuperado el 18 de enero de 2018 de https:/ /verdadabierta.com/el-duro-paso-de-la-paz-por-elcongreso/?sf_paged=2

Verdad Abierta. 2017, 16 de noviembre. “¿Corte Constitucional dejó a medias la justicia transicional?" Recuperado el 10 de enero de 2018 de https://verdadabierta.com/corte-constitucional-dejo-a-medias-la-justicia-transicional/

Verdad Abierta. 2017, 23 de noviembre. "Implementación de la JEP." Recuperado el 18 de enero de 2018 de https://verdadabierta.com/implementacion-de-la-jep-persiste-la-deuda-con-las-victimas/

Walter, Barbara. 2002. Committing to Peace. Princeton: Princeton University Press.

YanHass. 2017. Track semanal de Opinión Pública 13 de Marzo 2017. Recuperado el 13 de febrero de 2018 de http:/ / www.yanhaas.com/yanhaaspoll/YanHaasPoll13Mar2017.pdf

Paola Fajardo-Heyward es Ph.D. en Ciencia Política de la Universidad de Binghamton (SUNY). Actualmente es profesora asociada del Departamento de Ciencia Política de Canisius College (Buffalo) y directora del Programa de Relaciones Internacionales y del Programa de Estudios Latinoamericanos de Canisius College. Su investigación se concentra en el tema de los derechos humanos, derechos de la mujer y su relación con la economía política. Email: fajardop@canisius.edu 